\title{
Assessing pain in children with intellectual disabilities
}

\author{
Lynn M Breau PhD R Psych ${ }^{1}$, Chantel Burkitt ${ }^{2}$
}

LM Breau, C Burkitt. Assessing pain in children with intellectual disabilities. Pain Res Manage 2009;14(2):116-120.

Children with intellectual and developmental disabilities suffer more often from pain than their typically developing peers. Their pain can be difficult to manage, and assessment is often complicated by their limited communication skills, multiple complex pain problems and the presence of maladaptive behaviours. However, current research does provide some guidance for assessing their pain. Although self-report is an alternative for a small number of higher-functioning children, observational measures have the most consistent evidence to support their use at this time. For this reason, the Noncommunicating Children's Pain Checklist - Postoperative Version is recommended for children and youth 18 years of age or younger. However, other measures should be consulted for specific applications. Changes in function and maladaptive behaviour should also be considered as possible reflections of pain. In addition, children's coping skills should be considered because improving these may reduce the negative impact of pain.

Key Words: Intellectual disability; Pain assessment; Pediatric pain

\section{Évaluation de la douleur chez les enfants ayant un déficit intellectuel}

\begin{abstract}
Souvent, les enfants qui souffrent de déficits intellectuels et de retards de développement éprouvent plus de douleurs que les enfants dont le développement est normal. Ces douleurs peuvent être difficiles à gérer et leur évaluation est compliquée par les problèmes de communication des patients, l'origine multiple et complexe de leurs douleurs et leurs comportements mésadaptés. Toutefois, la recherche actuelle offre certaines pistes pour l'évaluation de ces douleurs. Bien qu'un petit nombre d'enfants plus fonctionnels soient capables de signaler leurs douleurs, les preuves les plus cohérentes dont dispose à l'heure actuelle appuient le recours à des mesures d'observation. C'est pourquoi, on recommande l'application de la version post-opératoire de la Non-communicating Children's Pain Checklist chez les enfants et les jeunes de 18 ans et moins. D'autres critères peuvent cependant être utiles pour certaines applications spécifiques. Ainsi, on restera à l'affût des modifications du fonctionnement et du comportement, qui sont parfois des manifestations de la douleur. On fera également appel aux capacités d'adaptation des enfants, car l'amélioration de leurs stratégies d'adaptation peut atténuer l'impact négatif de la douleur.
\end{abstract}

$\mathrm{C}^{\mathrm{h}}$ hildren with intellectual disabilities (ID) now survive in greater numbers and live longer (1). However, they may have more pain than typical children because of their chronic physical problems, complex medical disorders, and more frequent injuries and medical procedures (2). The only study to develop a profile of their typical pain on a daily basis revealed that $35 \%$ of a community sample of children with moderate to profound ID had pain each week, and the average time they spent in pain per week was $9 \mathrm{~h}$ to $10 \mathrm{~h}(2)$. Furthermore, pain assessment tools exist for this group, but are not always used in clinical settings. Thus, it is believed this group suffers pain that could be better managed with current knowledge. The key to encouraging better management is better assessment, which allows for better detection and monitoring of pain and makes it less likely that pain will be discounted. However, pain assessment must take a step beyond objectivity to completeness when incorporating the realities of a child with pain, and his or her life within a complex internal and external world.

The present paper attempts to broadly address the pain of children with ID. Although structured pain assessment tools will be discussed and still form the bulk of the literature, the discussion will not end there. The use of more informal methods of examining a child's behaviour in context will be briefly explained and new data investigating children's pain coping strategies will be described. Furthermore, the need for continuity of pain assessment from childhood to adulthood for this group, who may mature physically far in advance of their cognitive and emotional development, will also be addressed through the presentation of a new adaptation of a child assessment tool for adults with disabilities.

\section{EARLY RESEARCH}

Early research into the pain of people with ID is scant. The focus in early writings was primarily to highlight individual cases, often representing abnormal responses to pain $(3,4)$. Reynell (5) conducted the first study to document consistency in pain behaviours in 1965. He reported evidence that children with ID experience pain under the same circumstances that most children would be expected to have pain, that their pain response was observable and that it did not vary due to the level of impairment.

Case studies (6-8) dominated the literature for 30 years after Reynell's first report. By 1995, however, a new wave of more objective studies began to appear; they focused on the development of pain assessment tools for children and/or adults with ID. Giusiano et al (9) were the first to report results suggesting that a standardized tool was possible. They recorded pain behaviour during physical examinations of 100 individuals aged two to 33 years in a residential setting. Soon after, Fanurik et al (10) interviewed parents regarding children's pain behaviour. Their results suggested pain behaviour may vary with children's level of ID. Of those patients with mild or moderate ID, $57 \%$ were said to make verbal statements about their pain. In contrast, $45 \%$ of parents of children with severe to profound ID reported that their child exhibited some combination of indirect behaviours when in pain, with crying (22\%) and behavioural or emotional changes (10\%) being the most commonly reported individual signs of pain. These two groupings mirror the two major types of pain assessment considered to have potential for children with ID - self-report and observation of behaviour.

${ }^{1}$ School of Nursing and Departments of Psychology and Pediatrics, Dalhousie University, and Pediatric Complex Pain Team and Division of Child Neurology, IWK Health Centre; ${ }^{2}$ Department of Psychology, St Mary's University, Halifax, Nova Scotia

Correspondence: Dr Lynn M Breau, Pediatric Pain Research, IWK Health Centre, 5850 University Avenue, PO Box 9700, Halifax, Nova Scotia B3K 6R8. Telephone 902-470-7483, fax 902-470-7709, e-mail lbreau@dal.ca 


\section{PAIN ASSESSMENT FOR CHILDREN WITH ID}

Since these first studies appeared, the literature has grown considerably. The bulk has focused on development of observational assessment tools. However, some reports of research regarding children's ability to use self-report have appeared.

\section{SELF-REPORT OF PAIN}

Self-report is frequently cited as the gold standard of pain assessment. Because it plays a central role in the literature for other populations, and because clinicians often prefer to use self-report as a first-line assessment technique, it is important to consider it as a possibility when assessing pain in individuals with ID.

A recent study (11) investigated the self-report skills of children with ID by having them rate situations that could cause pain. Fourteen children with mild to moderate ID rated the pain of a person depicted in vignettes using a $100 \mathrm{~mm}$ visual analogue scale (VAS) of pain and the Faces Pain Scale - Revised (12). They also rated how much pain they would experience if they were in the same situation. The vignettes portrayed individuals in pain due to a burn from a casserole, falling from a bicycle, falling from roller skates and a vaccination. The children then described the quality of the pain each event would cause. The children's pain ratings for both the vignettes and the pain they would feel in that situation varied depending on the cause of pain, suggesting they made a distinction between the different types of pain. They also provided up to nine words to describe the quality of the pain for each event - a number similar to that reported by typical children of a similar mental age. Finally, their descriptions were appropriate for the pain depicted (eg, burning and pinching). These results suggest a basic ability to provide self-report, despite mild to moderate ID.

In another study, Benini et al (13) examined the self-report skills of 16 children with mild to moderate ID. Children were administered $1 \mathrm{~h}$ of training on the use of pain tools before receiving a venipuncture, then completed original and modified versions of self-report tools. These included a $10 \mathrm{~cm}$ VAS and a set of four natural wood cubes from $1 \mathrm{~cm}^{2}$ to $5 \mathrm{~cm}^{2}$ reflecting pain that 'didn't hurt at all' to pain that 'hurt very badly'; the original Eland Color Scale (14), which depicts a picture of a body that the child uses to indicate pain location, and an adapted version with the body parts enlarged; and the Wong-Baker FACES Pain Rating Scale (15), along with an adapted version with fewer faces. There were no differences in children's ability to use the scales based on level of ID. However, pain ratings did vary due to scale group (original or modified), and more children were capable of completing the modified than the original scales. Nevertheless, even with the modified scales, only approximately one-half of the children were capable of providing an intensity rating or location that seemed appropriate. Interestingly, they also reported that fear reduced success in their study.

Overall, the abilities of children to complete self-report scales in the study by Benini et al (13) appear to be less than in the study by Zabalia et al (11). This likely reflects a difference in the two situations. In the first study, children rated hypothetical pain, while in the second, they rated their own pain due to venipuncture. Research with the general population indicates that cognitive abilities are reduced during pain $(16,17)$, and children with ID are not likely exempt from this effect. Thus, the abilities children display during 'practice' with a tool may not reflect their ability to use it while in pain. Further evidence is needed before self-report can be recommended as a first-line assessment approach for children with even mild ID.

\section{OBSERVATIONAL PAIN ASSESSMENT TOOLS}

A great deal of work has been performed toward generating tools for pain assessment for children with ID since the 1990s. There is a small literature collection regarding tools designed for typically developing children when used for children with ID, such as the Faces, Legs, Activity, Cry and Consolability Scale $(18,19)$ and the Child Facial Coding System (20-22). However, because the scope of the present paper does not allow for in-depth discussion of their use and possibilities, the reader is referred to other publications for more information regarding them (23). Several groups have created tools for children, including the Échelle Douleur Enfant San Salvador (DESS), the Paediatric Pain Profile, the Non-communicating Children's Pain Checklist (NCCPC) and the Pain Indicator for Communicatively Impaired Children (9,24-26). New scales are emerging for pain in adults, including the Pain and Discomfort Scale, the Chronic Pain Scale for Nonverbal Adults with Intellectual Disabilities and the Noncommunicating Adult Pain Checklist (NCAPC) (27-29). Sufficient data to begin to judge validity and reliability are limited for some of these tools and scales at this time; however, readers are encouraged to seek information regarding ongoing evidence to support the literature as it grows.

\section{DESS}

Giusiano et al (9) published a paper describing item generation and analysis of the DESS in 1995. In a second study, Collignon and Giusiano (30) reduced the original 22 items to 10 . They also reported that a score of 2 indicated 'pain is possible', while a score of 6 indicated 'definite pain needing treatment'. One strength of this scale is that it was generated with data from both children and adults. This gives it potential for use across the lifespan. However, this may also mean that behaviours specific to children may not have been included in the final scale because item selection was based on data from a mixed age group. Several other factors weaken the scale's psychometrics. At a most basic level, overlap in item content is a problem because the presence of crying is included in several items. This means that multiple scoring of the same observed behaviour (crying) could potentially lead to a score reflecting pain. The DESS also requires items to be rated in relation to the child's typical behaviour. This may be of benefit in some situations, but it also makes the tool less valid when observers do not know the child's typical behaviour and can make it difficult to generalize scores across settings in which the child's typical behaviour varies. Finally, validation of the DESS was conducted in French only. Research on the English translation is needed to confirm the validity of an English version. Overall, the DESS shows promise, but needs more research before clinical use with children with ID can be recommended.

\section{Paediatric Pain Profile}

The Paediatric Pain Profile was developed by Hunt et al (25) by conducting interviews with 21 caregivers of children with ID and administering questionnaires to 121 children. From an original pool of 56 items, a set of 20 was selected by administering the tool to a second set of 46 parents and conducting item analysis to identify redundant items. Inter-rater reliability appeared to 
be good between parents and a caregiver, and scores were significantly lower after medication was administered. A cut-off score was also provided for moderate pain. In a second study (31) conducted with a subgroup of the original sample, the authors examined scores from videotape collected at home during specific daily activities, such as getting dressed and eating, that were believed to be painful for children with chronic pain conditions but not for children without chronic pain. Unfortunately, the cut-off score to detect pain differed from that reported in the first study and a different method of computing scores was used, making it unclear which method should be used clinically. One positive attribute of the scale is that this research group has generated a package that caregivers can complete to document extensive information about a child's pain history. This could be particularly helpful for children who have chronic or recurrent pain. Nonetheless, with only two published studies, some change in the cut-off scores reported and data from only one sample, a larger evidence base is needed before the Paediatric Pain Profile can be fully acceptable for clinical use.

\section{NCCPC}

Development of the NCCPC began in the mid 1990s. The original scale included 30 items in seven categories: vocal, eating/ sleeping, social/personality, facial expression, activity, body and limbs, and physiological (24). The NCCPC - Postoperative Version (NCCPC-PV) was then developed from this original scale and was investigated for assessing postoperative pain (32). This version did not include items from the eating/sleeping subscale and the yes/no responses were replaced by ratings of whether each item was observed 'not at all', 'just a little', 'fairly often' or 'very often' during 10 min observations. A cut-off score for moderate to severe pain was developed. A total score of 11 was equivalent to a score of 3 or greater of 10 on a $10 \mathrm{~cm}$ VAS and was able to detect $88 \%$ of children with clinically significant pain. Later, a score of 6 to 10 was determined to be able to detect mild pain (a score of less than 3 of 10 on a $10 \mathrm{~cm}$ VAS) with $75 \%$ accuracy. An important finding of the study was that interrater reliability was good because one observer was a parent or primary caregiver, while the other was a researcher who had not met the child. This was the first evidence that previous experience with a specific child was not needed to assess their pain.

The original NCCPC was also revised (NCCPC-R) for the home setting. This 30 -item version also included scores of the frequency of behaviours (33). Scores based on $2 \mathrm{~h}$ observations of children by their parents differed significantly for children who experienced pain during the observations and for those who did not. A total score of 7 detected pain in $84 \%$ of cases. A key finding of this study was that children's individual total NCCPC-R scores were consistent for two distinct episodes of pain that were separated in time and may have come from different sources. This was the first definitive evidence that the pain behaviour of individual children with ID is consistent over time.

The NCCPCs have been translated into several languages. A recent study (34) of 24 children in a rehabilitation hospital indicated that a Swiss-German translation had good reliability and validity when used by parents or caregivers. It revealed that a cut-off score of 5 was more appropriate for that version, highlighting the need to validate translated scales. A French translation of the NCCPC-PV, developed in Canada and France, is also currently being examined in hospitals in those countries. A 5 min observation period was also tested in this project to assess whether the feasibility of the NCCPC-PV could be improved. Preliminary data for the translated scale, called the Grille d'évaluation de la douleur - déficience intellectuelle, was based on 77 participants aged three to 57 years. It suggests that scores increase after surgery and may be similar to those found with the English version (35). Mean preoperative scores were below 7, while mean postoperative scores were over 14 .

Overall, the NCCPCs have the most evidence of psychometric soundness to support clinical use with children with ID at this time. More studies have been published using the NCCPCs than for the other two scales described here combined, and research has been conducted by different groups in different countries examining children's pain in different settings, including homes, residential centres, rehabilitation settings and acute care hospitals. For clinical use, the NCCPC-PV is recommended because its shorter observation period (currently $10 \mathrm{~min}$ ) increases clinical feasibility. Cut-off scores for mild pain (a total score of 6 to 10) and moderate to severe pain (a total score of 11 or greater) mean the NCCPC-PV also provides more information about the severity of pain than the NCCPC-R.

\section{ASSESSING PAIN ACROSS THE LIFESPAN}

Pain assessment in adults with ID

As youth with ID transition into adulthood, limitations in communication and behaviour not typical for adults without ID may continue to make assessment of their pain challenging. The difficulties may also be greater because observational methods are not as common for adults, which means observers may be less experienced at noting possible behavioural indications of pain. This can mean that tracking chronic pain problems becomes difficult in late adolescence and early adulthood. To address this need, we conducted a pilot study to assess the psychometric properties of the NCCPC-R for individuals over 18 years of age with ID (29).

Two staff members at an adult residential centre watched 16 residents simultaneously for two 5 min periods (pain; no pain). They also rated each resident's pain with a $10 \mathrm{~cm}$ VAS. NCCPC-R scores differed significantly between the pain and no-pain conditions. Item analyses revealed, however, that neither the eating/sleeping, nor the items 'jumping around', 'screaming' and 'floppy', were sensitive to pain. Subsequent analyses of a revised 24-item scale indicated it was sensitive to pain, internally consistent (Cronbach's alpha $=0.86$ ), and significantly correlated with the VAS pain ratings $(\mathrm{r}=0.67)$. Interrater reliability was also good (intraclass correlation coefficient $=0.83$ ). A new cut-off score of 10 was calculated, providing $94 \%$ sensitivity and $87 \%$ specificity for the presence of pain. Overall, the revised 24-item scale, which we are calling the Chronic Pain Scale for Nonverbal Adults with Intellectual Disabilities (CPS-NAID), appears to have sound psychometric properties. A strength of the scale is that it consists of a subset of items found in the NCCPC-R and NCCPC-PV. Thus, comparison can be made between scores of young adults on the CPS-NAID and their scores as an adolescent on the NCCPCs to assist in monitoring long-term conditions. Nonetheless, this scale has only been evaluated in one study, and caution should be taken before using it in clinical situations until further evidence of its psychometric soundness is accumulated. 
Another group has conducted similar evaluations of the NCCPC for use for acute pain in adults with ID in a residential setting. After detailed item analyses based on videotapes of 228 institutionalized adults with mild to profound ID, they retained 14 of the original 27 items of the NCCPC-PV, making changes to four (27). Their new scale, the NCAPC, was more sensitive to pain than the NCCPC-PV when ratings for 89 residents were compared. They also determined that interrater reliability of the scale was good when observers from a variety of health care backgrounds coded a subset of the videotapes of residents receiving injections (36). The fact that some items of the original NCCPC-PV have been reworded makes it somewhat more difficult to compare scores on this scale for a young adult to those he or she may have obtained with the NCCPC-PV as an adolescent. However, for immediate assessment, these studies suggest that it may be more appropriate to use the NCAPC for acute procedural pain in young adults with ID than either the NCCPC-PV, designed for children, or the CPS-NAID, designed for chronic pain in adults.

\section{BEYOND PAIN BEHAVIOUR}

Ratings of pain intensity, through self-report, and ratings of pain behaviour are only the beginning of pain assessment when approaching the task from a bioecological perspective (37). Other aspects of the child's behaviour should also be addressed. Self-injury may be a cue that pain is present and it may also assist with locating pain (38). Changes in functioning may also indicate that pain is present. In a recent study (39), we found that children displayed significantly more abilities on days when they were pain free than on days they had pain, and pain impacted all areas of function (communication, daily living, social and motor skills).

\section{Assessing pain coping}

In addition to attempting to assess pain so that we can make efforts to reduce it, improving a child's function when pain is present is also a major goal of pain assessment. This means that the child's own impact on the pain becomes relevant. It is believed that active coping strategies aimed at directly changing pain or at functioning despite pain, such as distraction or problem solving, are more effective than passive strategies aimed at avoiding pain or surrendering control over the pain (40). However, only one study has looked at pain coping in children with ID. Using the Pediatric Pain Coping Inventory (PPCI), Zabalia and Duchaux (41) found that children with ID more frequently sought social support as a method of coping with their painful experiences compared with literature that studied typical children. We sought to extend these findings by having parents of children with ID complete the parent version of the PPCI and by asking youth with mild to moderate ID directly about their experiences and coping strategies through an interview study using a phenomenological approach.

Preliminary results from 59 parents indicated that their children were most likely to use problem solving and least likely to use cognitive refocusing (42). Coping style was not related to age, but higher scores on the NCCPC-R vocal subscale were related to greater use of seeking social support as a coping strategy, suggesting vocal pain behaviour may, in part, reflect an attempt to seek social support by these children.
Having a lower mental age (but not chronological age) and being female was related to seeking social support or striving to be alone, whereas having a higher mental age and being male was associated with cognitive refocusing or problem solving.

Data for five youth interviews were collected and analyzed (43), and all five reported pain within the past three months. Preliminary analyses suggest that youth use problem solving most often, such as asking for medication, and attempt to rest and be alone when in pain. Some youth described seeking social support as a method of coping, but this approach was less prevalent than reported by parents. Few reported use of cognitive self-instruction or cognitive refocusing. Some also reported that cognitive refocusing did not work, so they resorted to focusing on the pain. When asked whether their chosen style of coping was helpful, the youth often concluded that it did not decrease the amount of pain or distress, with the exception of asking for medication. Youth rarely reported that they tried multiple coping strategies during the same pain episode. In contrast to parents' reports via the PPCI, the preliminary findings suggest that high-functioning youth with ID who took part in this interview study cope with pain in similar ways to typically developing youth, albeit through the use of one strategy at a time.

\section{SUMMARY}

Pain assessment for children with ID should follow the same principles as for other groups. Although self-report can be the best and most direct way to obtain information about pain intensity if the child is capable of doing so while in pain, there is little evidence at this time to support the standard use of self-report for many children with ID. When possible, a thorough pain assessment should include some estimate of the child's level of intellectual functioning; results of formal testing can be used to determine whether the child is likely to be capable of understanding the concepts necessary to complete a self-report tool. Practice, based on hypothetical situations, can be one way to assess the child's ability to use self-report. Problems with this task may indicate the child is not likely to be able to use the tool in question during actual pain. The NCCPC-PV should be used when self-report is not possible or when there are concerns about a child's self-report ability. When chronic or recurrent pain is present, multiple applications of a pain tool can provide information regarding temporal patterns of pain and can help to unravel behavioural changes due to pain from changes due to other factors, such as illness or sleep problems. Developing a record of the child's pain history, using a format such as that provided with the Paediatric Pain Profile (25), can also be useful in cases of chronic or multiple pain, or for detecting new emerging pain problems. Patterns in self-injury and functioning can also be used to help determine whether pain is present, where it may be located and the extent to which it impacts the child. Finally, new research suggests that children with ID do use different coping strategies when they have pain, with differing results. Thus, assessment of how the child copes with pain may help in directing the child to either use their most effective strategy, or to try new strategies if those in their repertoire are not useful for them. Although there is some indication that children with ID can provide reports about their coping during pain when they are not in pain, parent report may be the most valid way of understanding a child's coping strategies and skills at this time. As our knowledge about pain assessment for children with ID 
emerges, it is important that we implement all evidence-based strategies available. The particular vulnerabilities of this group require that we take special care in assessing their pain so that we can be proactive in managing their pain.

ACKNOWLEDGEMENTS: Dr Lynn M Breau is supported by a New Investigator Salary Award from the Canadian Institutes of Health Research. This paper was a component of the Special Series on Measurement of Pain in Children presented in Pain Research $\mathcal{E}$ Management, 2009, volume 14, issue 1.

\section{REFERENCES}

1. Patja K, Iivanainen M, Vesala H, Oksanen H, Ruoppila I. Life expectancy of people with intellectual disability: A 35-year follow-up study. J Intellect Disabil Res 2000;44:591-9.

2. Breau LM, Camfield CS, McGrath PJ, Finley GA. The incidence of pain in children with severe cognitive impairments. Arch Pediatr Adolesc Med 2003;157:1219-26.

3. Couston TA. Indifference to pain in low-grade mental defectives. Br Med J 1954;1:1128-9.

4. Stengel E, Oldham AJ, Ehrenberg AS. Reactions of low-grade mental defectives to pain. J Ment Sci 1958;104:434-8.

5. Reynell JK. Post-operative disturbances observed in children with cerebral palsy. Dev Med Child Neurol 1965;7:360-76.

6. Mette F, Abittan J. Essais d'évaluation de la douleur chez le polyhandicapé. Annales Kinésithérapie 1988;15:101-4.

7. Collignon P, Porsmoguer E, Behar M, Combe JC, Perrin C. L'automutilation: Expression de la douleur chez le sujet deficient mental profond. La douleur de l'enfant quelles resposes? Paris: UNESCO, 1992:15-21.

8. Collignon P, Giusiano B, Porsmoguer E, Jimeno ME, Combe JC. Difficultés du diagnostic de la douleur chez l'enfant polyhandicapé. Ann Pediatr 1995;42:123-6.

9. Giusiano B, Jimeno MT, Collignon P, Chau Y. Utilization of a neural network in the elaboration of an evaluation scale for pain in cerebral palsy. Methods Inf Med 1995;34:498-502.

10. Fanurik D, Koh JL, Schmitz ML, Harrison RD, Conrad TM. Children with cognitive impairment: Parent report of pain and coping. J Dev Behav Pediatr 1999;20:228-34.

11. Zabalia M, Jacquet D, Breau LM. Rôle du niveau verbal sur l'expression et l'évaluation de la douleur chez des sujets déficients intellectuals. Doul Analg 2005;2:65-70.

12. Hicks CL, von Baeyer CL, Spafford PA, van Korlaar I, Goodenough B. The Faces Pain Scale - Revised: Toward a common metric in pediatric pain measurement. Pain 2001;93:173-83.

13. Benini F, Trapanotto M, Gobber D, et al. Evaluating pain induced by venipuncture in pediatric patients with developmental delay. Clin J Pain 2004;20:156-63.

14. Eland JM. The child who is hurting. Semin Oncol Nurs 1985;1:116-22.

15. Wong DL, Baker CM. Pain in children: Comparison of assessment scales. Pediatr Nurs 1988;14:9-17.

16. Eccleston C, Crombez G. Pain demands attention: A cognitiveaffective model of the interruptive function of pain. Psychol Bull 1999;125:356-66

17. Dick B, Eccleston C, Crombez G. Attentional functioning in fibromyalgia, rheumatoid arthritis, and musculoskeletal pain patients. Arthritis Rheum 2002;47:639-44.

18. Voepel-Lewis T, Malviya S, Tait AR. Validity of parent ratings as proxy measures of pain in children with cognitive impairment. Pain Manag Nurs 2005;6:168-74.

19. Malviya S, Voepel-Lewis T, Burke C, Merkel S, Tait AR. The revised FLACC observational pain tool: Improved reliability and validity for pain assessment in children with cognitive impairment. Paediatr Anaesth 2006;16:258-65.

20. Chambers CT, Cassidy KL, McGrath PJ, Gilbert CA, Craig KD. Child Facial Coding System - Revised Manual. Halifax: Dalhousie University and University of British Columbia, 1996.
21. Oberlander TF, Gilbert CA, Chambers CT, O'Donnell ME, Craig KD. Biobehavioral responses to acute pain in adolescents with a significant neurologic impairment. Clin J Pain 1999;15:201-9.

22. Hadden KL, von Baeyer CL. Global and specific behavioral measures of pain in children with cerebral palsy. Clin J Pain 2005;21:140-6.

23. Breau LM, McGrath PJ, Zabalia M. Assessing pediatric pain and developmental disabilities. In: Oberlander T, Symons FJ, eds. Pain in Children and Adults with Developmental Disabilities. Baltimore: Paul H Brookes, 2006:149-72.

24. Breau LM, McGrath PJ, Camfield C, Rosmus C, Finley GA. Preliminary validation of an observational pain checklist for persons with cognitive impairments and inability to communicate verbally. Dev Med Child Neurol 2000;42:609-16.

25. Hunt A, Goldman A, Seers K, et al. Clinical validation of the paediatric pain profile. Dev Med Child Neurol 2004;46:9-18.

26. Stallard P, Williams L, Velleman R, Lenton S, McGrath PJ, Taylor G. The development and evaluation of the pain indicator for communicately impaired children (PICIC). Pain 2002;1-2:149.

27. Lotan M, Ljunggren EA, Johnsen TB, Defrin R, Pick CG, Strand LI. A modified version of the Non-communicating Children's Pain Checklist - Revised, adapted to adults with intellectual and developmental disabilities: Sensitivity to pain and internal consistency. J Pain 2009. (In press)

28. Phan A, Edwards CL, Robinson EL. The assessment of pain and discomfort in individuals with mental retardation. Res Dev Disabil 2005;26:433-9.

29. Burkitt C, Breau LM. Pilot study of the feasibility of the Non-communicating Children's Pain Checklist - Revised for pain assessment for adults with intellectual disabilities. J Pain Manag 2009. (In press)

30. Collignon P, Giusiano B. Validation of a pain evaluation scale for patients with severe cerebral palsy. Eur J Pain 2001;5:433-42.

31. Hunt A, Wisbeach A, Seers K, et al. Development of the paediatric pain profile: Role of video analysis and saliva cortisol in validating a tool to assess pain in children with severe neurological disability. J Pain Symptom Manage 2007;33:276-89.

32. Breau LM, Finley GA, McGrath PJ, Camfield CS. Validation of the Non-communicating Children's Pain Checklist - Postoperative Version. Anesthesiology 2002;96:528-35.

33. Breau LM, McGrath PJ, Camfield CS, Finley GA. Psychometric properties of the Non-communicating Children's Pain Checklist Revised. Pain 2002;99:349-57.

34. Kleinknecht M. Reliability and validity of the German language version of the 'NCCPC-R'. Pflege 2007;20:93-102.

35. Breau LM, Harth M, Lévêque C, Hennequin M, Bureau N, Wood C. Validation en français de la grille d'évaluation de la douleur - déficience intellectuelle. Douleurs: Évaluation, Diagnostic, Traitement 2008;9(Suppl 4):48. (Abst)

36. Lotan M, Moe-Nilssen R, Ljunggren AE, Strand LI. Reliability of the Non-Communicating Adult Pain Checklist (NCAPC), assessed by different groups of health workers. Res Dev Disabil 2009;30:735-45.

37. Breau LM. A bio-ecological approach to pediatric pain assessment. J Pain Manag 2008;1:247-55.

38. Breau LM, Camfield C, Symon DN, et al. Pain and self-injurious behaviour in neurologically impaired children. J Pediatr 2003;142:498-503.

39. Breau LM, Camfield CS, McGrath PJ, Finley GA. Pain's impact on adaptive functioning. J Intellect Disabil Res 2007;51:125-34.

40. Van Damme S, Crombez G, Eccleston C. Coping with pain: A motivational perspective. Pain 2008;139:1-4.

41. Zabalia M, Duchaux C. Stratégies de faire-face à la douleur chez des enfants porteurs de déficience intellectuelle. Revue Francophone de la Déficience Intellectuelle 2007;17:53-64.

42. Burkitt C, Breau LM, Zabalia M. Evaluation parentale des stratégies de faire-face à la douleur des enfants et adolescents atteints de déficience intellectuelle. Douleurs: Évaluation, Diagnostic, Traitement 2008;9(Suppl 4):50. (Abst)

43. Burkitt C, Breau LM, Zabalia M. Stratégies de faire face à la douleur chez des enfants atteints de déficience intellectuelle: Une approche qualitative par l'entretien. Douleurs: Évaluation, Diagnostic, Traitement 2008;9(Suppl 4):50. (Abst) 


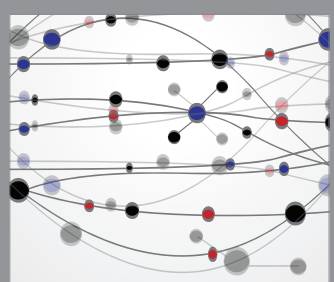

The Scientific World Journal
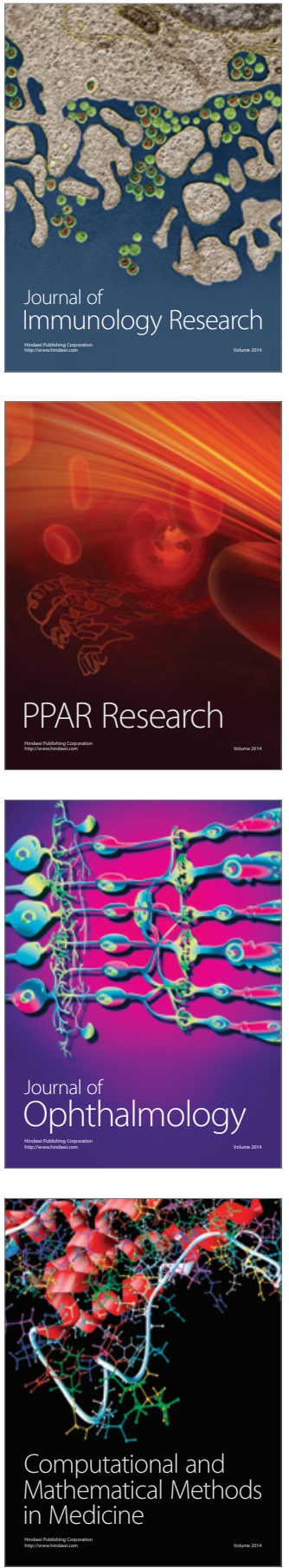

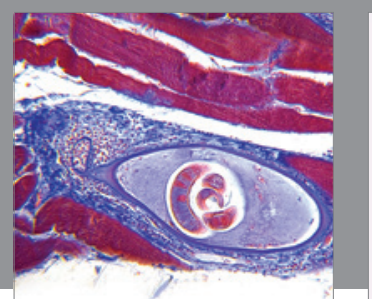

Gastroenterology Research and Practice

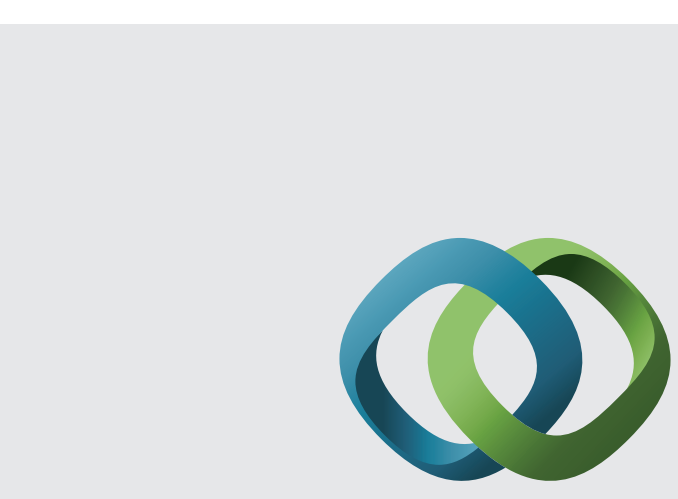

\section{Hindawi}

Submit your manuscripts at

http://www.hindawi.com
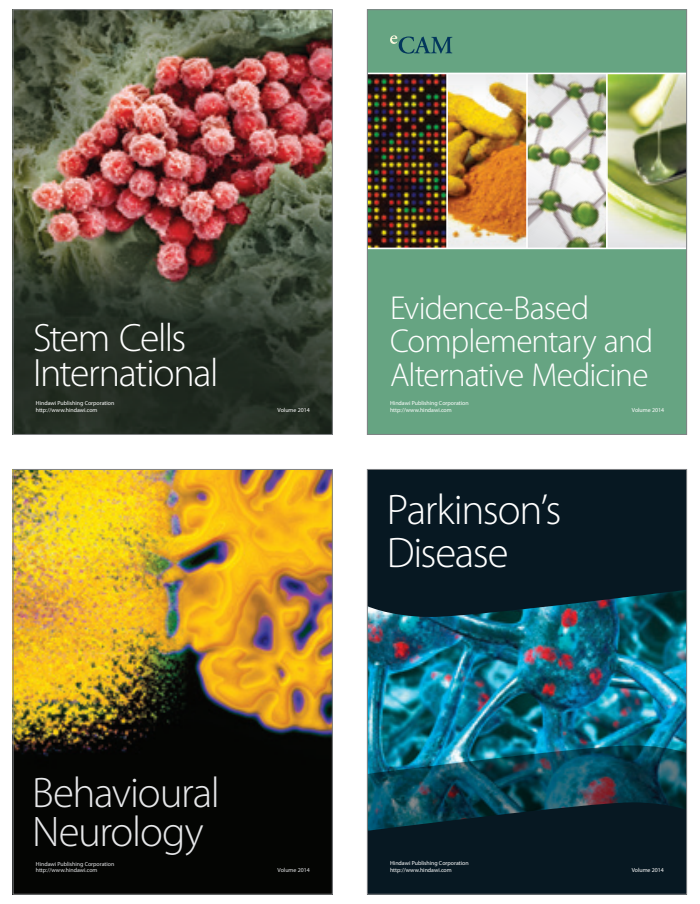
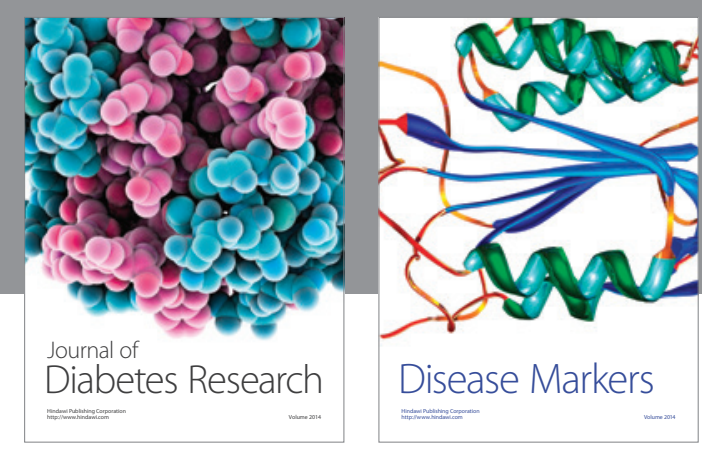

Disease Markers
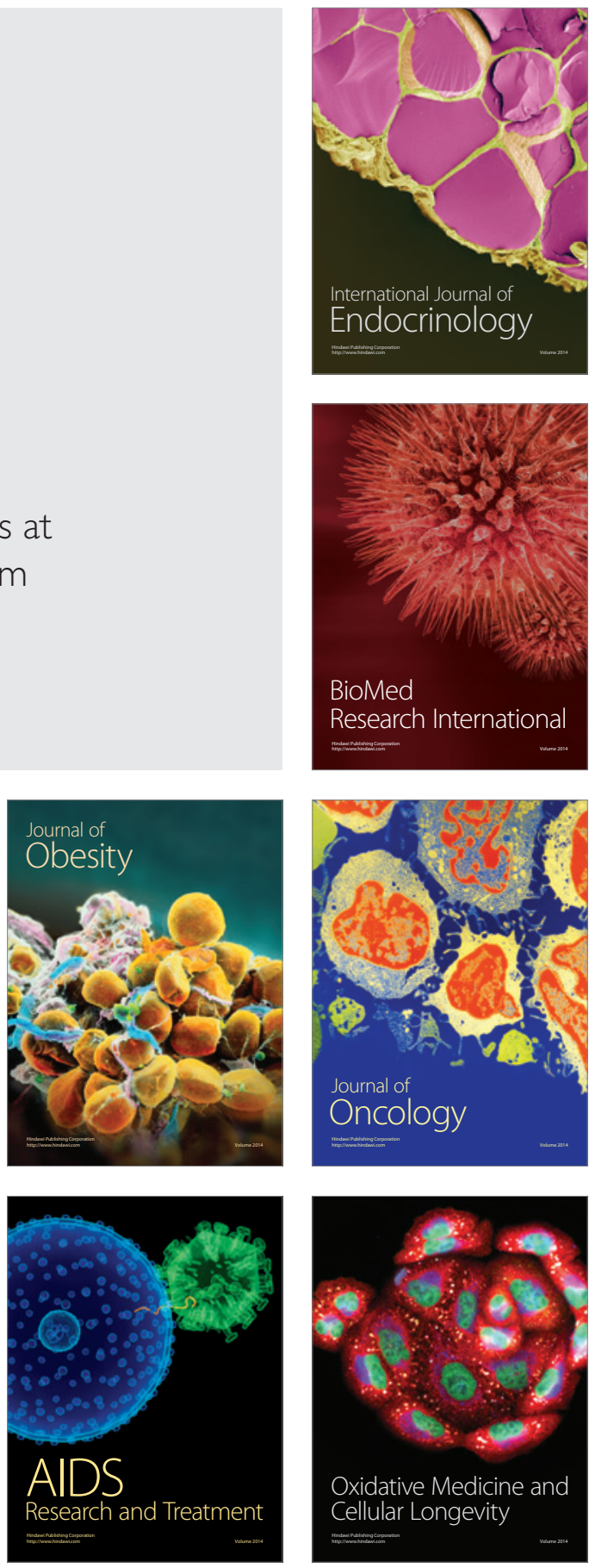